This item was submitted to Loughborough's Research Repository by the author.

Items in Figshare are protected by copyright, with all rights reserved, unless otherwise indicated.

\title{
Evaluation of a fuel-efficient urban delivery vehicle
}

PLEASE CITE THE PUBLISHED VERSION

https://doi.org/10.1177/0954407016689511

PUBLISHER

(C) IMechE. Published by SAGE

VERSION

AM (Accepted Manuscript)

PUBLISHER STATEMENT

This work is made available according to the conditions of the Creative Commons Attribution-NonCommercialNoDerivatives 4.0 International (CC BY-NC-ND 4.0) licence. Full details of this licence are available at: https://creativecommons.org/licenses/by-nc-nd/4.0/

\section{LICENCE}

CC BY-NC-ND 4.0

\section{REPOSITORY RECORD}

Midgley, Will, and D. Cebon. 2017. "Evaluation of a Fuel-efficient Urban Delivery Vehicle". Loughborough University. https://hdl.handle.net/2134/35110. 


\title{
Evaluation of a Fuel-Efficient Urban Delivery Vehicle
}

\author{
W.J.B. Midgley and D. Cebon \\ Submitted to Proc. IMechE, Part D, Journal of Automotive Engineering, February, 2016 \\ Accepted for publication, December, 2016
}

\section{Abstract}

A novel, fuel-efficient, articulated urban delivery vehicle is developed and tested. The vehicle has a path-following steering system on the semitrailer which improves its manoeuvrability in narrow city streets. This enables the payload to be increased from $39.4 \mathrm{~m}^{3}$ of freight on a conventional rigid delivery vehicle to $84.2 \mathrm{~m}^{3}$ on this articulated counterpart: leading directly to up to $33 \%$ fuel saving per unit of freight task.

The vehicle is also equipped with a hydraulic regenerative braking system which stores energy in hydraulic accumulators during braking events and releases this energy back to accelerate the vehicle in subsequent motion. The design of this system and the field testing programme are described. The experimental tests are used to determine hydraulic losses and to validate a mathematical model of the vehicle and regenerative braking system.

Finally, the validated mathematical model is used to perform a parametric study for the vehicle operating on various standard driving cycles. It is found that operating the regenerative braking system with engine stop-start and optimized accumulator pre-charge pressures can reduce fuel consumption by 9 to $18 \%$ compared with the baseline vehicle, depending on the drive cycle. When combined with the performance improvements due to the trailer steering system and additional payload, this gives an overall reduction in fuel consumption of $35-42 \%$.

\section{Introduction}

The single most effective intervention for reducing the fuel consumption of a heavy goods vehicle is to increase its carrying capacity [1]. This reduces the number of vehicles needed for a given freight task. Provided the vehicle is fully loaded, it can lead to substantial fuel savings. For example, Odhams et al [1] showed that carrying freight on 44t articulated vehicles instead of $20 \mathrm{t}$ rigid trucks reduces the fuel consumption per tonne.km by approximately $30 \%$. However, geometric constraints, imposed by narrow streets in UK and European cities can limit the use of full size tractor-semitrailer vehicles unless shortened trailers are used (reducing the benefit) or trailer steering is used to improve manoeuvrability. Consequently, significant effort has gone into developing computer-controlled, path-following trailer steering systems with accurate tracking fidelity [2].

Another way to significantly reduce the fuel usage of heavy goods vehicles (HGVs) in urban environments, is regenerative braking [1]. Previous work has shown that hydraulic regenerative braking systems are smaller and lighter than electrical hybrids for these vehicles [3]. Some commercial manufacturers such as Parker Hydraulics [4, 5] and Eaton Hydraulics [6-8] have built hydraulic hybrids for refuse and urban delivery applications. These technologies are installed on rigid vehicles and integrate directly into the drivetrain. Artemis Intelligent Power have a solution for urban buses. The manufacturer claims that it reduces fuel consumption by up to $25 \%$, where the hybrid system is installed in parallel with the engine [9]. 
Previous work has shown that a parallel hydraulic regenerative braking system can reduce the fuel consumption of an urban HGV by $21 \%$ on idealised stop-start cycles and up to $17 \%$ on legislative drive cycles [10]. A further advantage of such a system is that the regenerative braking system can be used to 'launch' the vehicle from rest, enabling the engine to be switched off during idle periods and switched back on during the early part of the acceleration phase. This paper builds on the previous work to specify such a hydraulic regenerative braking system [10,11], and to design and build a prototype for a semtrailer with integrated steering axles. It uses the results of tests on this vehicle to inform changes to the vehicle model developed in [10-12]. This validated model is then used to determine the benefits of the system 'as-built' over a range of drive cycles, as well as the benefits of a realistic 'commercial system'. It is assumed that the provision of trailer steering enables use of a tractor-semtrailer configuration instead of a rigid vehicle for this freight task. The trailer steering system is described elsewhere [2], and is not investigated here.

\section{System Modelling and Specification}

The details of the system model are given in [10] and summarised here. A pair of hydraulic accumulators (one at high pressure (HP) and one at low pressure (LP)) are connected via a valve block to in-wheel fixed-displacement pump-motors (PMs), as shown in the high-level outline of the hydraulic circuit in Figure 1. (The full schematic is available in [13]). When the vehicle is accelerating, the fluid from the HP accumulator is passed through the PMs to the LP accumulator providing a positive (accelerating) torque. When decelerating, the opposite happens: a braking torque is applied by the PMs, and fluid is forced from the LP to the HP accumulator.

For an articulated vehicle such as that modelled in this and previous papers, the regenerative braking system is intended for the trailer axles, with one PM per wheel. The fuel saving could possibly be increased if a hybrid tractor unit is used as well, e.g. [14]. If only the trailers are used for regenerative braking, there is insufficient tyre friction force available to recover all of the energy available [11].

An overview of the computer model of the hybrid vehicle system, developed in [11,12] is given in Figure 2. A driver model is used to generate a throttle demand, which is then passed to the engine and the regenerative braking controller. The regenerative braking controller makes decisions on whether to use the regenerative braking system based on the current state of the accumulators and the demanded torque, using a so-called 'greedy' strategy, where energy is used and captured at the earliest opportunity. Previous studies give more detail on the vehicle model and its validation [1, 3, 10-12], and the reasoning behind the choice of a greedy controller over a more sophisticated one [15].

\section{Hardware System}

The final specification from [10] was used as a starting point for the construction of the hydraulic regenerative braking system. Relevant values for the system properties are given in Table 1. Design constraints limited the selection of components and so the specification was changed between the original design in [10] and that of the final built system. The final specifications are also given in Table 1, and the reasons for any differences are discussed below. An existing experimental 'B-link' trailer with actively-steered axles [16] was adapted to incorporate the braking hardware. 


\subsection{Mechanical}

In order to ensure that the vehicle can navigate urban areas, the trailer requires steering such as that introduced by Jujnovich et al. [2, 16, 17]. Given this constraint, in-wheel PMs were chosen, to remove the need for any drivetrain to be added to the trailer. Fixed displacement PMs were used because they are small, light, robust and fit easily into the wheel ends, enabling the axles to steer.

However, this choice placed further constraints on the design of the system due to the required articulation between the wheels and the trailer frame. The two main degrees of freedom are shown in Figure 3: rotation between the wheel and the axle to allow steering of the wheels through roughly $\pm 25^{\circ}$; and rotation of the axle about the trailing arm pivot point, which is produced by movement in the vertical direction to accommodate suspension travel.

These constraints create challenges in routing the fluid to the PMs, which were mounted on the wheel ends. Consequently, flexible hose was used in conjunction with swivel joints to transport the fluid from the trailer frame to a custom-designed manifold located above the steering kingpin (see Figures 3 and 4). Figure 4 also shows the custom-designed steering knuckle-stub-axle unit, which includes fluid paths and a drain line for the PMs. In order to attach the PMs to the wheels, new wheel hubs had to be designed and manufactured, and the existing brake rotors modified.

The accumulators and associated valves and instrumentation were installed in a frame located in the rear of the trailer, to allow easy access during testing. A photograph of the finished system is given in Figure 5. The masses for the components added to the vehicle are given in Table 2. It is envisaged that this equipment would be installed under the trailer in a commercial system, so as not to impact on the volumetric capacity of the trailer. It would therefore not require the heavy frame which was built for experimental convenience.

\subsection{Hydraulics}

The original specification given in [10] assumed carbon-fibre accumulators from a particular supplier. However, when this regenerative braking system was built, carbon-fibre accumulators were temporarily unavailable. Instead, steel accumulators from a different supplier were used. A simplified schematic of the system for one axle is given in Figure 1.

Two high-pressure accumulators and three low-pressure accumulators were used so as to minimise the effects of heat dissipation from the compressed gas (though these are represented as single accumulators in Figure 1 for simplicity). After consultation with the manufacturers of the in-wheel PMs, the precharge of the LP accumulators was changed from 12.5bar to 27bar, in order to prevent the PMs from cavitating. In addition, the precharge of the $\mathrm{HP}$ accumulators was limited to 97bar, due to operational constraints.

The high- and low-pressure accumulators were linked to the wheels through custom-made manifolds, which were then linked to custom-made, low-loss, three-position hydraulic valves (the 'Regenerative braking valve' in Figure 1). The valves were linked to manifolds near the trailing arm (see Figure 3) by large-bore hydraulic hose. These 'Frame rail manifolds' are shown schematically in Figure 3, and are represented as a fluid restriction in Figure 1, due to the pressure drop encountered when fluid passes through them. From these manifolds, swivel joints and smaller-bore ultra-flexible hydraulic hose were used to deliver the fluid to the manifold which sits atop the steering knuckle. This manifold was then connected to the stubaxle as mentioned above, to allow the fluid to pass through to the PMs. The PMs were the same specification as given in [10]. 
Also shown in Figure 5 is a hydraulic fluid tank (at atmospheric pressure). This tank and the associated charge pump (not visible in Figure 5) were included for experimental convenience in order to ensure a safe working environment in case any components or system settings needed to be changed. When changes were required, all of the fluid was vented to the tank, rendering the circuit safe to work on. When the changes were complete, the LP accumulators were re-pressurised using the charge pump, which was powered from batteries installed on the trailer, charged by the tractor unit's alternator.

In order to prevent catastrophic failure of the circuit, several safeguards were included: pressure relief valves set to the maximum circuit pressure (330bar); 'flow fuses', attached to the HP accumulators, that shut automatically if the flow passed the design threshold (1501/min); and software cut-outs that vent all fluid to the tank if the system breaches predefined pressure thresholds.

A pilot circuit runs in parallel with the primary hydraulic circuit, in order to provide pressure for the actuation of the regenerative braking valves. This circuit was pressurised from the LP accumulators and any pressure spikes were damped by a small additional hydraulic accumulator. Additional small accumulators were added to the drain line from the PMs, to prevent any large pressure spikes from damaging the circuit.

\subsection{Instrumentation}

In order to operate the system and to monitor the system status, a network of sensors and controllers was required, as shown in Figure 6.

A global controller running MATLAB's xPC Target software co-ordinated communication between the different parts of the control and sensor network. The majority of the communication was via a controller area network (CAN) bus [18].

Local controllers (one per axle) monitored pressures in the circuit, and relayed this information, along with a real-time estimate of available torque, to the global controller where it was logged. These local controllers were also responsible for: monitoring of the system pressures to ensure safe operation; operating the pilot circuit to change the state of the regenerative braking valve; de-pressurising the system if any abnormal pressures or system states were encountered; and running the charge pump to charge the hydraulic circuit before testing.

An 'ICON' microcontroller communicated with accelerometers and a fuel flowmeter installed on the vehicle, and relayed these signals back to the global controller, where they were logged as in [12]. The global controller also communicated with an RT3000 GPS-inertial navigation unit [19], which provided accurate position and velocity information for logging test runs. A brake ECU running customised software sent instantaneous wheelspeeds to the global controller, which could demand a brake pressure from the brake ECU.

\section{System Testing}

After building and commissioning the regenerative braking system, it was tested in order to ascertain the performance, and to validate the existing regenerative braking system model described in [11]. 


\subsection{Test Location}

The tests were undertaken on the runway at Bourn Airfield, near Cambridge, UK. The tests were always run on the same part of the airfield, and run in both the south-east and northwest directions, to account for any variability in terrain and wind conditions.

\subsection{Test Cycles}

Given the limited area available for testing, only simple straight-line stop-start tests were possible. Two main types of test were undertaken: one set for characterising the flow-induced losses in the hydraulic system; and one for validation of the system model.

\subsubsection{Stop-start to Characterise Losses}

A significant parameter in the regenerative braking system model is the magnitude of the hydraulic losses in the system. Previous modelling studies on this system assumed loss coefficients based on experience and reference values for lengths of hydraulic hose and hose fittings. Given the novel and intricate layout of the fluid paths in this system (see Figure 4 for an example), it was important to characterise these losses to enhance the accuracy of the model.

The overall pressure losses $(\Delta P)$ from end-to-end along a fluid path were modelled using:

$$
\Delta P=\Delta P_{0}+k Q^{2}
$$

Where $k$ is the loss coefficient, $Q$ is the instantaneous flowrate and $\Delta P_{0}$ is the 'crack pressure' required to produce flow in the system.

For these tests, the wheel speed $(\omega)$ measured by the ABS controller was used to determine the instantaneous flowrate in the system:

$$
Q=d_{m} \omega
$$

where $d_{m}$ is the known fixed displacement of the in-wheel PM. Additional pressure transducers were added to the circuit in order to measure the end-to-end pressure drop and are labelled as Pressure gauges (PG) 1-5 in Figure 1. Several stop-start tests were conducted, ensuring adequate coverage of the operational flowrates of the system in both acceleration and deceleration mode. For these tests, the difference in pressure between the two pressure gauges was calculated at each timestep over the cycle.

Results from these tests for pressure test points at the accumulator outlet (PG 1) and the frame rail manifold inlet (PG 3) are given in Figure 7 as an example. In order to exclude transients from the calculation, only steady-state data (i.e. after a settling period of one second) was included in this calculation. This explains the lack of data for flowrates below $0.5 \times 10^{-3} \mathrm{~m}^{3} / \mathrm{s}$. Figure 7 also includes lines of best fit for the data using equation (1). Little difference was observed in the magnitude of losses between the front and rear axles, and this was well within experimental error.

A breakdown of losses for each section of the circuit is given in Table 3, where the rightmost column gives the percentage of pressure drop at full flow of each component when compared to the total pressure drop across the circuit. Due to the complex nature of the machined hub/knuckle, it was not possible to measure the pressure drop between the inlet to the manifold and the inlet to the PMs.

From Table 3 it is clear that the largest contributor to losses in the circuit at high flowrates is the section of pipe between the frame rail manifold and the knuckle manifold. This is unsurprising, in that this section of pipe has a smaller internal diameter than the rest of the circuit, and it also includes loss-inducing fittings such as the swivel joints. The final equation 
used in the model to characterise the overall pressure loss for both the front and rear axles was:

$$
\Delta P=13.9 \times 10^{6} Q^{2}+2.6
$$

where $\Delta P$ is in bar and $Q$ is the flowrate in $\mathrm{m}^{3} / \mathrm{s}$.

\subsubsection{Stop-start cycle}

In order to prove the effectiveness of the system, and provide test results against which the model could be validated, a series of stop-start tests were undertaken. The cycle used in [3] was a stop-start from $13.4 \mathrm{~m} / \mathrm{s}(30 \mathrm{mph})$ at $-/+0.15 \mathrm{~g}(1.47 \mathrm{~m} / \mathrm{s})$, intended to emulate a typical stop-start cycle in an urban environment. However, the PMs used on the vehicle have a maximum operational speed of $11.1 \mathrm{~m} / \mathrm{s}(40 \mathrm{~km} / \mathrm{h})$, above which they must be disengaged hydraulically. In addition, during testing it was found that the maximum safe deceleration was $0.9 \mathrm{~m} / \mathrm{s}^{2}$, above which experimental equipment in the truck cab became unstable. A further constraint on the test cycle was the limited runway length available for testing.

Taking these restrictions into consideration, the test cycle used in these stop-start tests was:

1. Accelerate to $11.1 \mathrm{~m} / \mathrm{s}(40 \mathrm{~km} / \mathrm{h})$

2. Start the logging equipment

3. Decelerate to a standstill over 12 seconds under the action of the regenerative braking system and the foundation friction brakes

4. Remain stationary for 5 seconds

5. Accelerate to $11.1 \mathrm{~m} / \mathrm{s}(40 \mathrm{~km} / \mathrm{h})$ over 17 seconds using a combination of the regenerative braking system and the truck engine using $2^{\text {nd }}$ and $4^{\text {th }}$ gears

As fully-automated acceleration and deceleration control of the system was not possible, the regenerative braking was operated manually: when the deceleration section of the test was started the system was switched into braking mode until it reached maximum pressure. During the acceleration section the system was switched into acceleration mode until the minimum pressure was reached in the HP accumulators. The driver acted as the velocity controller, to try and match the vehicle's deceleration profile to the desired one. A minimal number of gear changes were used because these were found to be a source of large variation between tests. The tests were run in both directions on the runway, in order to account for any variations in surface profile or elevation.

\section{Testing Results}

This section focuses on one particular set of test runs, in order to show the differences between the tests with and without regenerative braking.

\subsection{Stop-Start Cycles}

The speed-time trace of a stop-start cycle showing the results from comparable test runs (i.e. in the same direction and in similar conditions) with and without regenerative braking is shown in Figure 8, and the accompanying cumulative fuel used is shown in Figure 9.

The fuel usage data presented in Figure 9 has been taken from the fuel flowmeter as shown in Figure 2. This device produces pulses for each set volume of fluid that is injected into the engine. These pulses are then window averaged in order to obtain a flowrate versus time plot as shown in Figure 9. More details on this process are given in [12]. The speed data in Figure 
8 and the pressure data in Figure 10 and Figure 11 were taken directly from the RT3000 and the local pressure controllers, respectively.

The speed-time profiles with and without regenerative braking show two main differences. During the deceleration stage, there is a small difference between the rate at which the vehicle starts to decelerate because of the step-change in braking provided by the regenerative braking system. The same step-change is responsible for the change in deceleration rate at around 10 seconds - the regenerative braking system is switched off, as the pressure in the HP accumulator drops to the precharge pressure, and the driver must compensate for the sudden decrease in net braking force provided to the vehicle.

The second, more noticeable change is during the acceleration portion of the cycle. During the gear change at around 23 seconds, the vehicle continues to accelerate, as positive torque is still being supplied by the regenerative braking system. By contrast, the conventional vehicle decelerates during the gear change, as there is no positive torque being applied to the wheels.

In the cumulative fuel graph shown in Figure 9 the difference between the two tests during acceleration is clear. The regenerative braking system provides a positive torque, meaning that the engine has to provide less power to accelerate the vehicle, which in turn means that the vehicle requires less fuel. Some of this advantage is reduced because the vehicle continues to accelerate at a similar pace to the conventional vehicle after the gear change (23-30 seconds), but is recaptured again at the end of the cycle when the regenerative braking test starts to reduce the deceleration rate, and therefore fuel usage. In this test, the regenerative braking system reduced fuel usage by $17.5 \%$ (see Table 4 ).

\subsection{Comparison of Simulation and Experiment}

In order to make the model described in Section 3 match the practical test results more closely, several small changes were required. Firstly, a more accurate clutch model was added. Previous iterations of the model had focussed on higher-speed driving cycles and did not behave correctly when accelerating from a standstill. The new clutch model allowed for gradual matching of the engine and wheelspeeds when accelerating, where the previous model had neglected these effects. Secondly, the hydraulic losses in Eq. (3) were added in place of the assumed values that were used previously.

Finally, it was found that the previous model for the hydraulic accumulators was insufficient, as it did not take account of thermal effects when calculating the pressure in the accumulators. Instead, the previous model assumed the nitrogen in the accumulators behaved as an ideal gas undergoing adiabatic compression/expansion:

$$
P V^{\gamma}=\text { const }
$$

where $\gamma$ was 1.4 and $P$ and $V$ are pressure and volume, respectively. The widely-used Benedict-Webb-Rubin (BWR) equation of state [20-22] was used for modelling these effects:

$$
P=\rho R T+\left(B_{0} R T-A_{0}-\frac{C_{0}}{T^{2}}\right) \rho^{2}+(b R T-a) \rho^{3}+\alpha a \rho^{6}+\frac{c \rho^{3}}{T^{2}}\left(1+\gamma \rho^{2}\right) \exp \left(-\gamma \rho^{2}\right)
$$

where $P$ is the instantaneous pressure, $\rho$ is the density of the gas, $T$ is the gas temperature, $R$ is the gas constant and $A_{0}, B_{0}, C_{0}, a, \alpha, b, c, \gamma$ are constants that were obtained from [23] and given in Table 5 . The calculation of instantaneous pressure given a volume change in the nitrogen bladders in the accumulators was modelled using the approach given by Otis and Pourmovahed [22], and the thermal time constant was taken from experimental results to be 10 seconds. 
Comparisons between the improved model and the experimental results for the LP and HP accumulators are shown in Figures 10 and 11 respectively. These figures show good agreement (typically within 5bar) between the model and the experimental results. The large drop at the end of the HP trace, at around 27 seconds in Figure 11 is a transient due to the sudden closure of the low-pressure cut-off valve shown in Figure 1. The value of pressure after that point is incorrect, as this pressure transducer is located downstream of the accumulator, and the valve closing isolates the sensor from the accumulator pressure.

The results of simulating this improved model over the testing cycle are also shown in Figures 9 and 10. The model follows the experimental speed very closely, and the final fuel usage is accurate to within $3 \%$ for both the regenerative braking and conventional tests. There are, however, some notable differences between the model and the experimental tests during the acceleration portion of the cycle (20-25 seconds), and the final stages of the test (32-35 seconds).

Both of these differences are likely due to the incomplete nature of the engine map used in the model, which was taken from [12]. The experimental map was measured from steadystate tests, but is here being applied to a transient cycle, which also involves a clutch. The clutch modelling goes some way toward minimising this difference, but once the gear change is completed at around 25 seconds, it can be seen that the model matches the experimental results much more closely. Toward the end of the cycle, the fuel flow as predicted by the model starts to level off, before that of the test results. This is likely due to inaccuracies in the engine map at high rpm (revolutions per minute) - a human or automated driver would typically change gear before the engine rpm reached this level - but, as mentioned above, the number of gear changes was reduced in order to reduce variability between tests. The results of the various simulations are summarised in Table 4.

As mentioned above and shown in Table 2, the addition of the regenerative braking system also adds significant mass to the vehicle. The results given above were obtained using the same vehicle, with the regenerative braking system either disengaged (Case 1) or engaged (Case 2). It could be argued that this gives a disadvantage to the conventional vehicle because it is heavier than it would normally be. In order to account for this, the model was also run with a vehicle mass that did not include the regenerative braking hardware: $20982 \mathrm{~kg}$ instead of $22850 \mathrm{~kg}$ (see the masses in Table 4). This reduced the fuel usage by $10.6 \%$ (Case 5), compared to the $19.5 \%$ saving obtained by using the regenerative braking system (Case 4 ).

The system installed on the experimental vehicle was a prototype system, intended for experimentation and ease-of-access during testing. If a similar system were commercialised, it is likely that the added mass would be much lower. In particular, a hydraulic oil tank would not be required (the system would be constantly pressurised), lighter carbon fibre accumulators could be used [24], and a lighter subframe could be used. With these considerations, it is assumed that the final mass of a commercial system could be reduced by $60 \%$ (see Table 2). Simulating the model with this lighter regenerative braking system gives a fuel saving of $21.4 \%$ (Case 6, Table 4) over the conventional experimental results, or $11.8 \%$ over the modelled system without the added regenerative braking mass (Case 5, Table 4). This lightweight commercial system (Case 6) is the one used in the following section to characterise the benefits of the regenerative braking system over various stop-start driving cycles. 


\section{Evaluation of Fuel Consumption Benefits}

The four cycles used to compare the performance of the vehicle with the regenerative braking system to that of the baseline vehicle were the New European Drive Cycle (NEDC) [25], Heavy Heavy-Duty Diesel Truck-Transient cycle (HHDDT-T) [26], New York City cycle (NYC) [27] and Urban Dynamometer Driving Schedule (UDDS) [27]. The regenerative braking system started each cycle with the same amount or less stored energy than it finished the cycle with, in order to ensure that the model did not benefit from an undue advantage. This was achieved by equating the gas volumes at the start of the cycle, with the gas volumes at the end of the same cycle under the same conditions, by simulating the cycles several times, in a similar manner to [10].

The values used for the mass of the unladen vehicle are those given in Table 4 for 'With Commercial regenerative braking' (Case 6) and 'Without regenerative braking' (Case 5). The payload used for both vehicles was 8.4tonnes, obtained using a full volumetric load $\left(84.2 \mathrm{~m}^{3}\right)$ with an average freight density of $100 \mathrm{~kg} / \mathrm{m}^{3}$ as per [1]. The validated vehicle model with and without regenerative braking was simulated over the four drive cycles with this payload. This model was also used to simulate a 26tonne rigid using values from [1] and [28], as this is the vehicle against which the articulated regenerative braking vehicle with steering should be compared, see Table 6 .

The 'Energy Index by Volume' [1] (EIv) given by Eq (6) was used to compare these simulations to the vehicle simulated without regenerative braking, and the results are given in Table 7.

$$
\mathrm{EI}_{\mathrm{V}}=\frac{\text { Fuel Energy Used }}{\text { Payload Volume } \times \text { Distance Covered }}
$$

These results show only small decreases in $\mathrm{EI}_{\mathrm{v}}$ for 3 of the 4 drive cycles, and an increase in $\mathrm{EI}_{\mathrm{v}}$ for the NEDC cycle. However, it is worth noting that the accumulator precharge pressure for these simulations was the same as that for the practical tests: 90bar. However, a previous study [10] showed that changing the precharge pressure of the HP accumulator can double EIv savings. Running the model over these cycles for a range of precharge pressures gives an optimal point for EIv saving, and these points are given in Table 8, along with the EI saving if engine stop-start is used to turn the engine off during periods of idle in the cycle. Example results for Cases 5 and 6 are given in Figures 12 and 13 for the UDDS drive cycle, where the regenerative braking system has a precharge pressure of 200bar. Both figures show that the vehicle with regenerative braking (Case 6) has better fuel consumption than the standard vehicle (Case 5). It is also apparent from Figure 13 that the modified vehicle has better acceleration performance, because of the additional drive torque available from the hydraulic motors. This enables it to track the desired drive cycle a little more accurately than the unmodified vehicle.

These results are more promising than those in Table 7 because the increase in precharge pressure allows the system to store more energy. The system is most effective on the NYC cycle, where there is a large amount of stopping and starting and, as seen in previous studies, engine stop-start makes the most difference on this cycle as the vehicle spends a lot of time idling. In general, the engine stop-start system adds approximately two percentage points of $\mathrm{EI}_{\mathrm{v}}$ saving to the remaining cycles.

The comparatively high precharge pressure for the NEDC cycle is due to the relatively low number of stop-starts included in this cycle. Additionally, much of the cycle is at speeds which 
are too high to be considered urban, and are outside of the operating range of the regenerative braking system.

In general the savings due to the regenerative braking system are lower than expected from the previous studies, and this can be attributed to three main causes, the first being the very high pressure drops in the system. Due to the constraints on transporting fluid to the wheelends, the hydraulic circuit involves many changes of direction and changes in pipe diameter. These serve to increase the pressure drop in the system, which is most apparent at high speeds (see Figure 7), where the most energy can be harvested from the vehicle during deceleration.

The second cause that contributes to the reduction in effectiveness of the regenerative braking system is the system mass. In previous studies, the mass of the system was assumed to be significantly less than that of the finished system, and therefore contributed less toward increased fuel usage.

The third important factor is the updated accumulator model. In previous simulation studies, the accumulator model was simplistic, as the parameters of the final system were not known. Incorporating the time-dependent BWR model, which takes account of heat transfer within the accumulator decreases the efficiency of the system, as energy 'leaks' from the accumulators as heat over the course of the cycles. These three factors combine to reduce the energy savings from this regenerative braking system.

Each of these three factors could be mitigated in order to increase the efficiency of the system. A commercial system using carbon fibre accumulators and lightweight components built into the trailer axles could significantly reduce the added weight Similarly, the mechanical and hydraulic systems could be integrated better in a 'clean-slate' design, rather than retrofitting the hydraulic hardware as in this project, and would therefore incorporate fewer sharp changes of direction and hose diameter. Thirdly, it has been shown that adding foam in the gas bladder of a hydraulic accumulator can markedly improve their heat transfer characteristics, reducing the energy lost to heat during operation [29, 30]. With these mitigation strategies, a much more promising increase in fuel efficiency would be possible.

\section{Conclusions}

1) The hydraulic regenerative braking system has been successfully built, installed and tested on a semitrailer.

2) Fuel use was reduced by $17.5 \%$ during simple stop-start tests.

3) Fuel use was reduced by $8.6 \%$ over the simple stop-start cycles when the added mass from the regenerative braking system was taken into account.

4) The previous vehicle model was updated to incorporate hydraulic loss coefficients and to include more sophisticated accumulator modelling, and agreed with the testing results to within $5 \%$.

5) The experimental regenerative braking system is heavier than previously expected, but several opportunities exist for reducing mass, including the use of carbon fibre accumulators instead of the current steel accumulators.

6) The three factors of increased vehicle mass, large hydraulic loss factors and heat transfer within the hydraulic accumulator lead to a system which is less effective than expected from previous studies.

7) The regenerative braking system would provide an EIv reduction of 7.5\%, 6.6\%, $4.1 \%$ and $12.2 \%$ over the UDDS, HDDDT-T, NEDC and NYC drive cycles. 
8) The regenerative braking system with engine stop-start would provide an $\mathrm{EI}_{\mathrm{v}}$ reduction of $9.2 \%, 8.2 \%, 6.5 \%$, and $18.1 \%$ over the UDDS, HDDDT-T, NEDC and NYC cycles.

9) Changing from a 20t rigid to a $13.6 \mathrm{~m}$ articulated vehicle with regenerative braking system and stop-start was shown to reduce energy consumption by a total of $35 \%$ for the UDDS drive cycle. This consists of $25.8 \%$ due to the capacity increase and a further $9.2 \%$ from regenerative braking and stop-start. For the NYC cycle the capacity increase gives a $23.9 \%$ benefit, and the regenerative braking and stop-start give a further $18.1 \%$, giving a total reduction in fuel consumption of $42 \%$. 


\section{Figures}

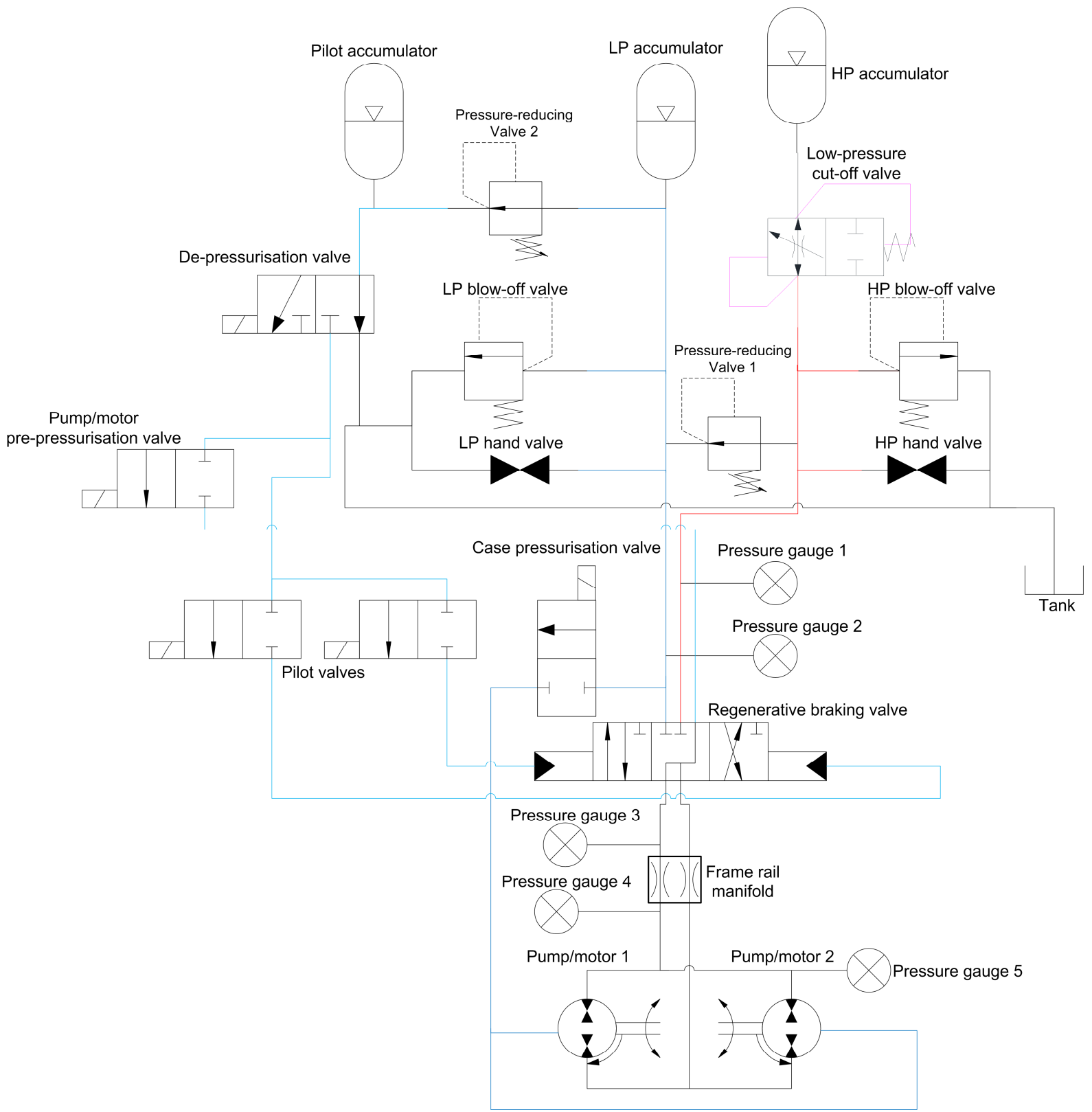

Figure 1: Hydraulic schematic diagram of the regenerative braking system. (Red: high-pressure lines; blue: low-pressure lines; light-blue: pilot pressure lines.) 


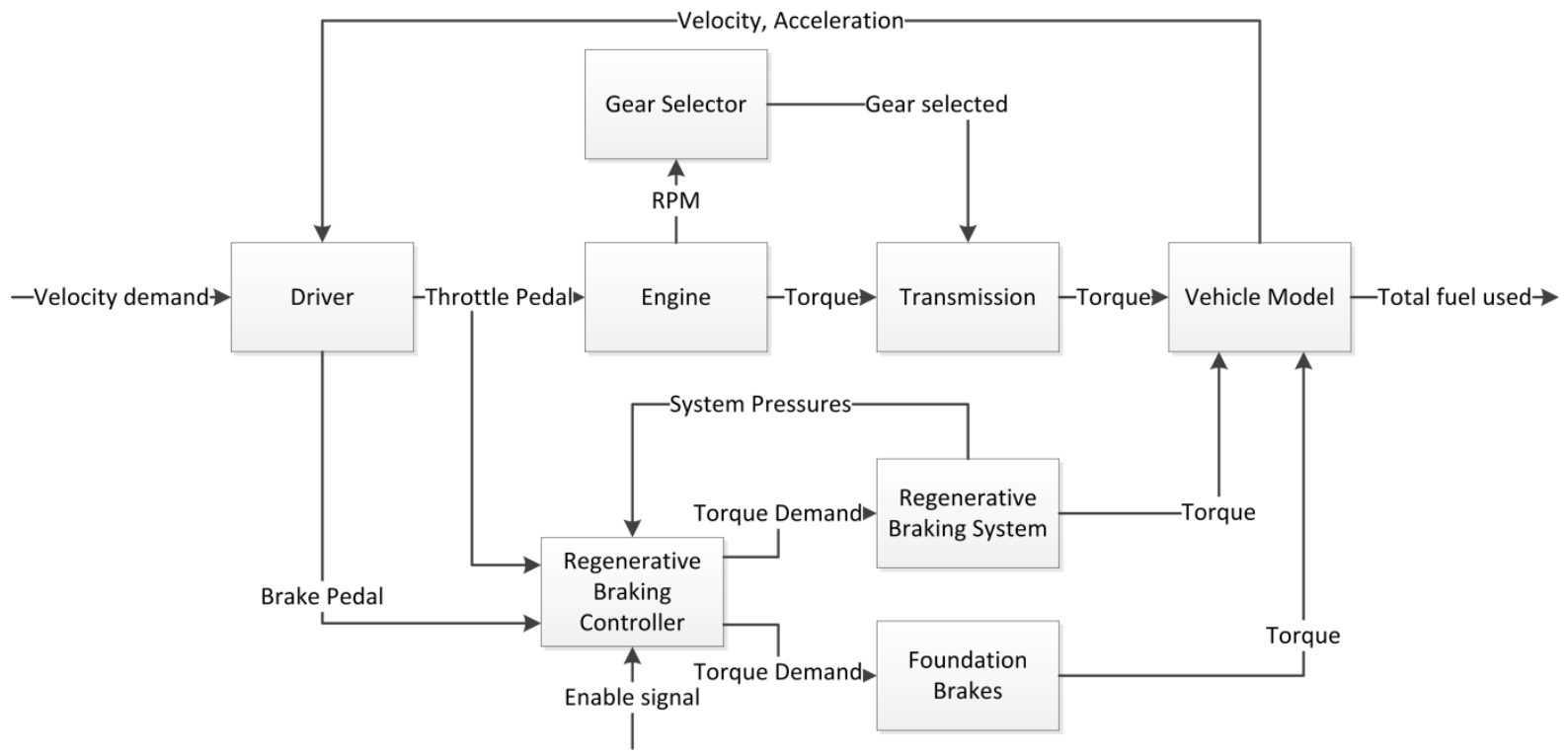

Figure 2: Overall system schematic

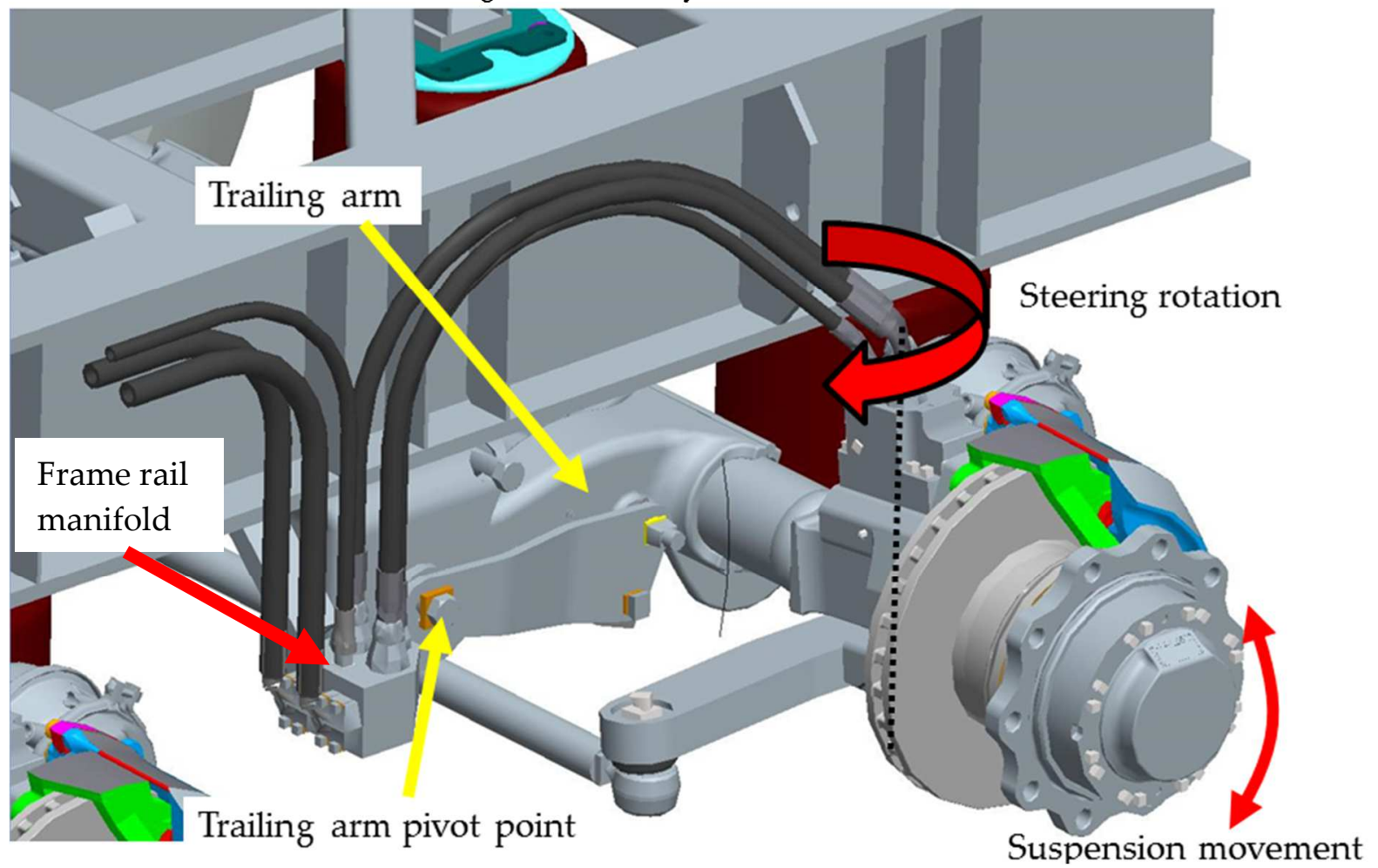

Figure 3: Degrees of freedom of the wheel-end 


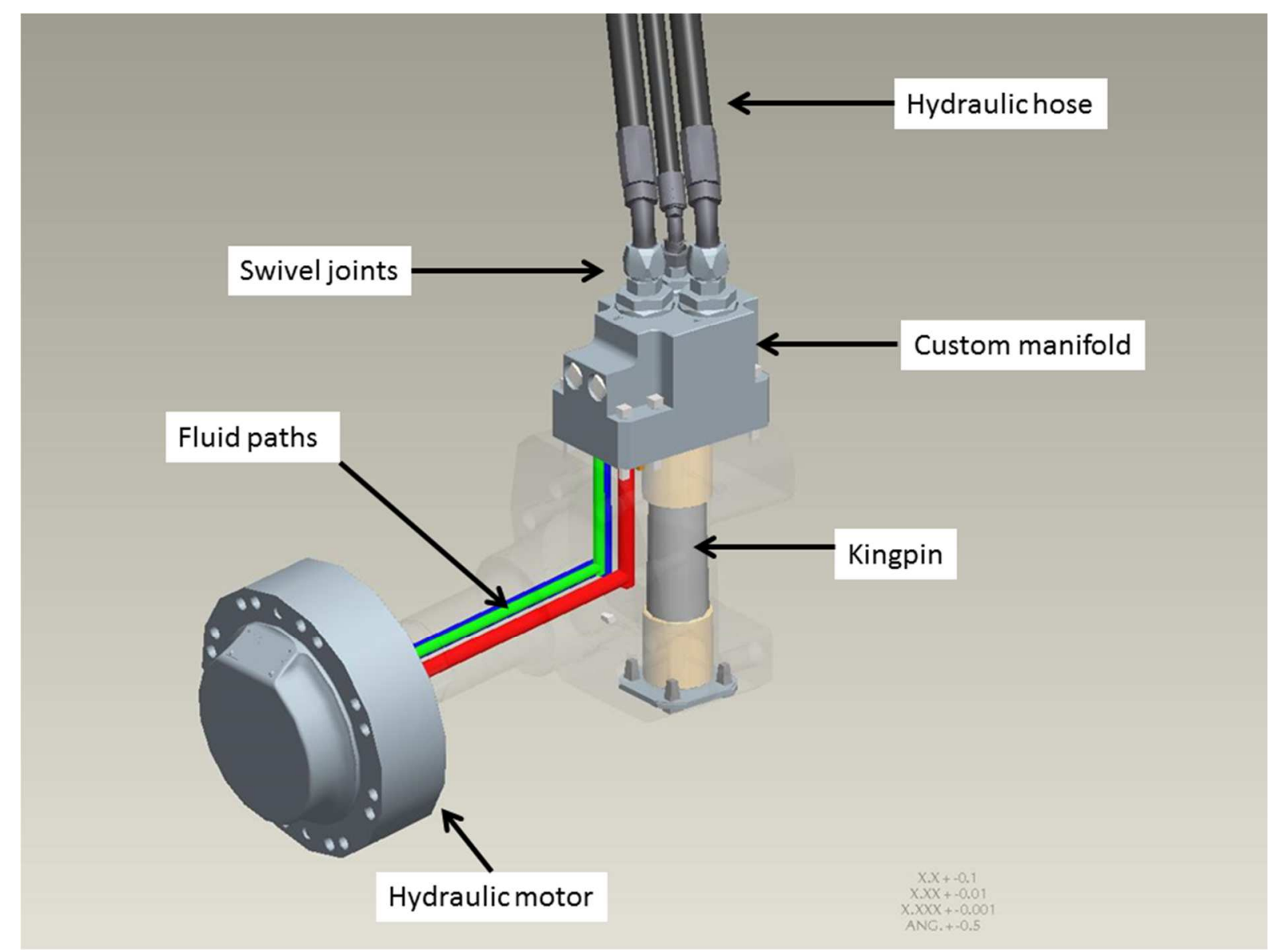

Figure 4: Hydraulic routing and custom manifold, with swivel joints 


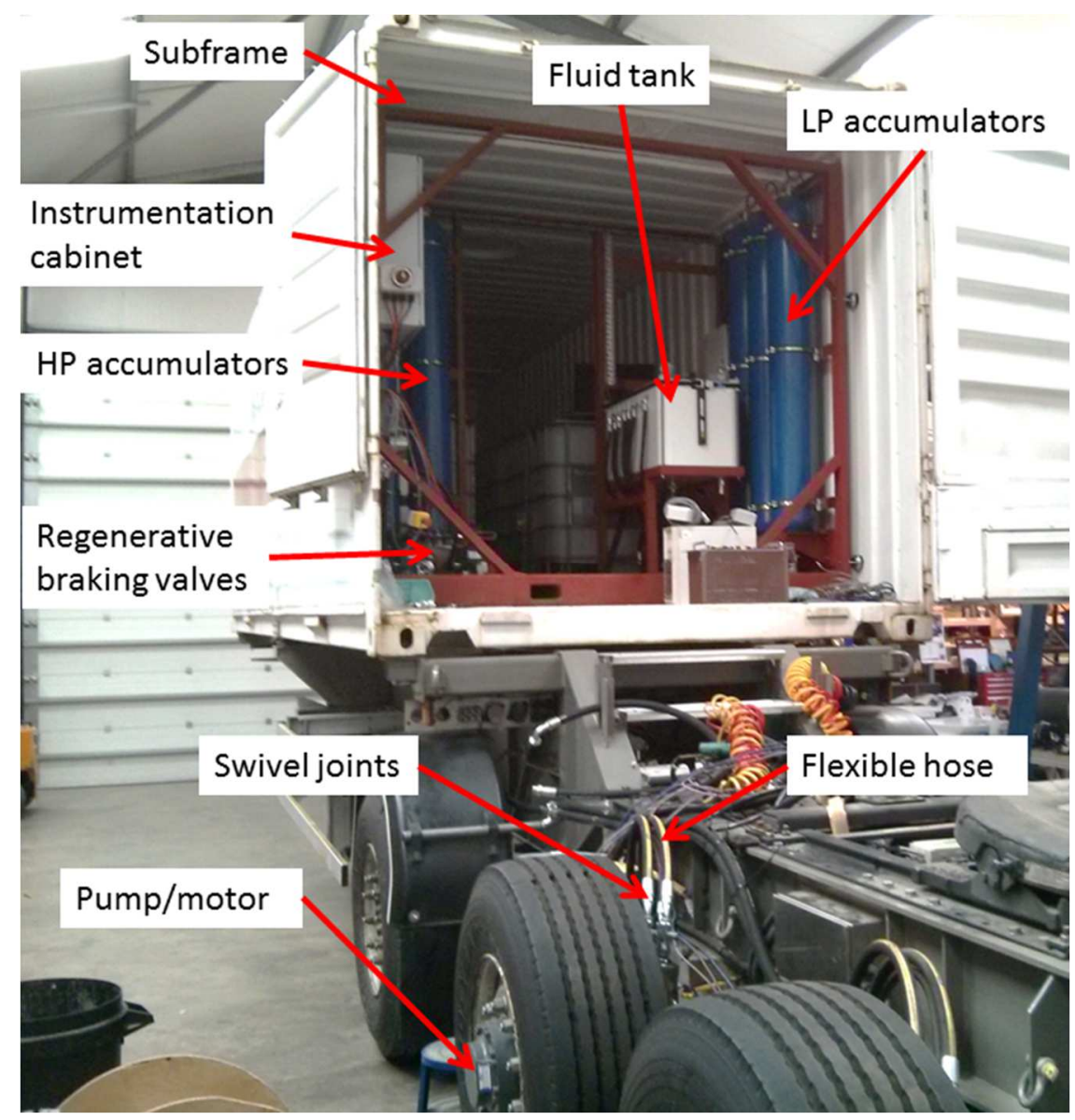

Figure 5: Photo of experimental system installed on the B-link trailer

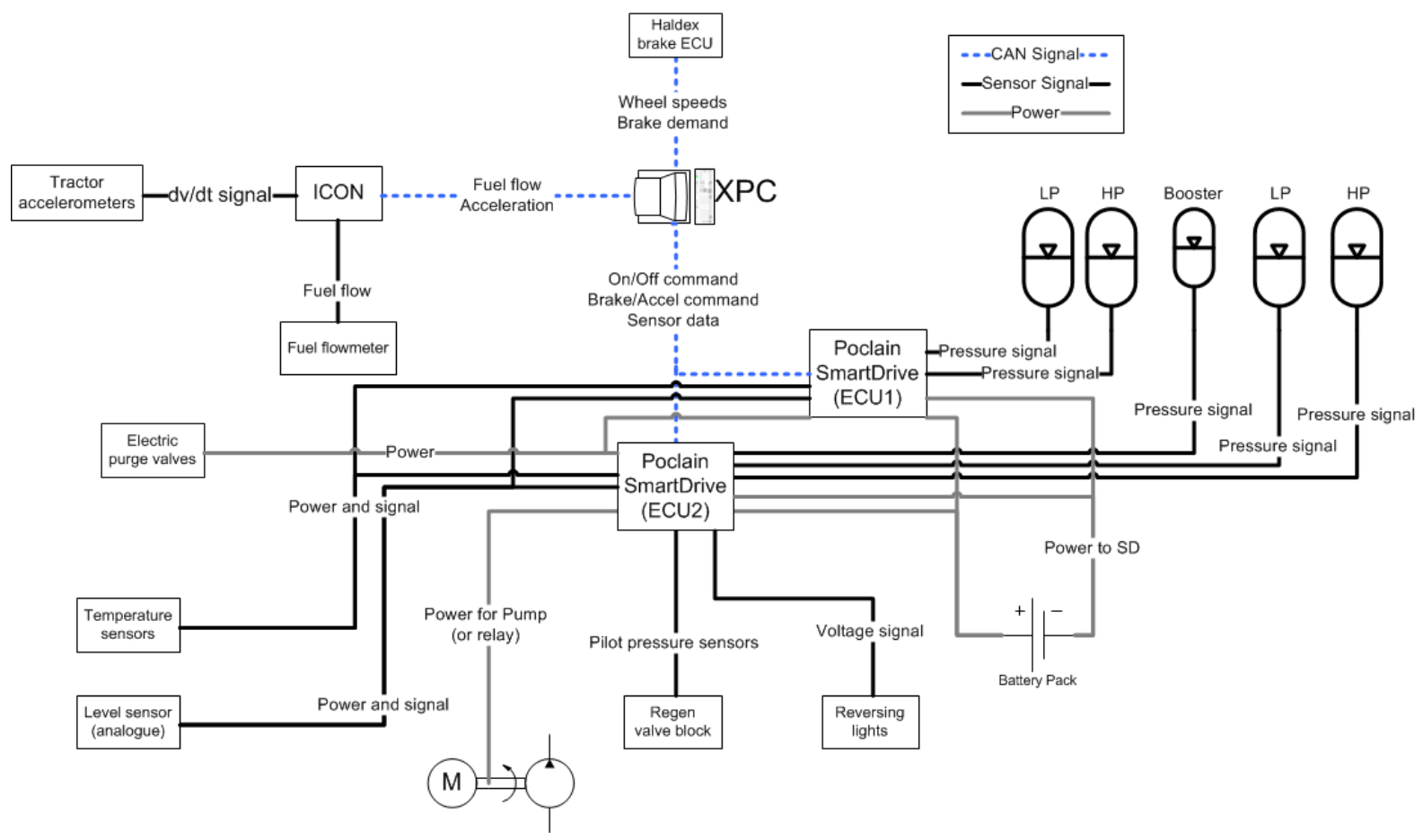

Figure 6: Schematic of instrumentation and controller interaction 


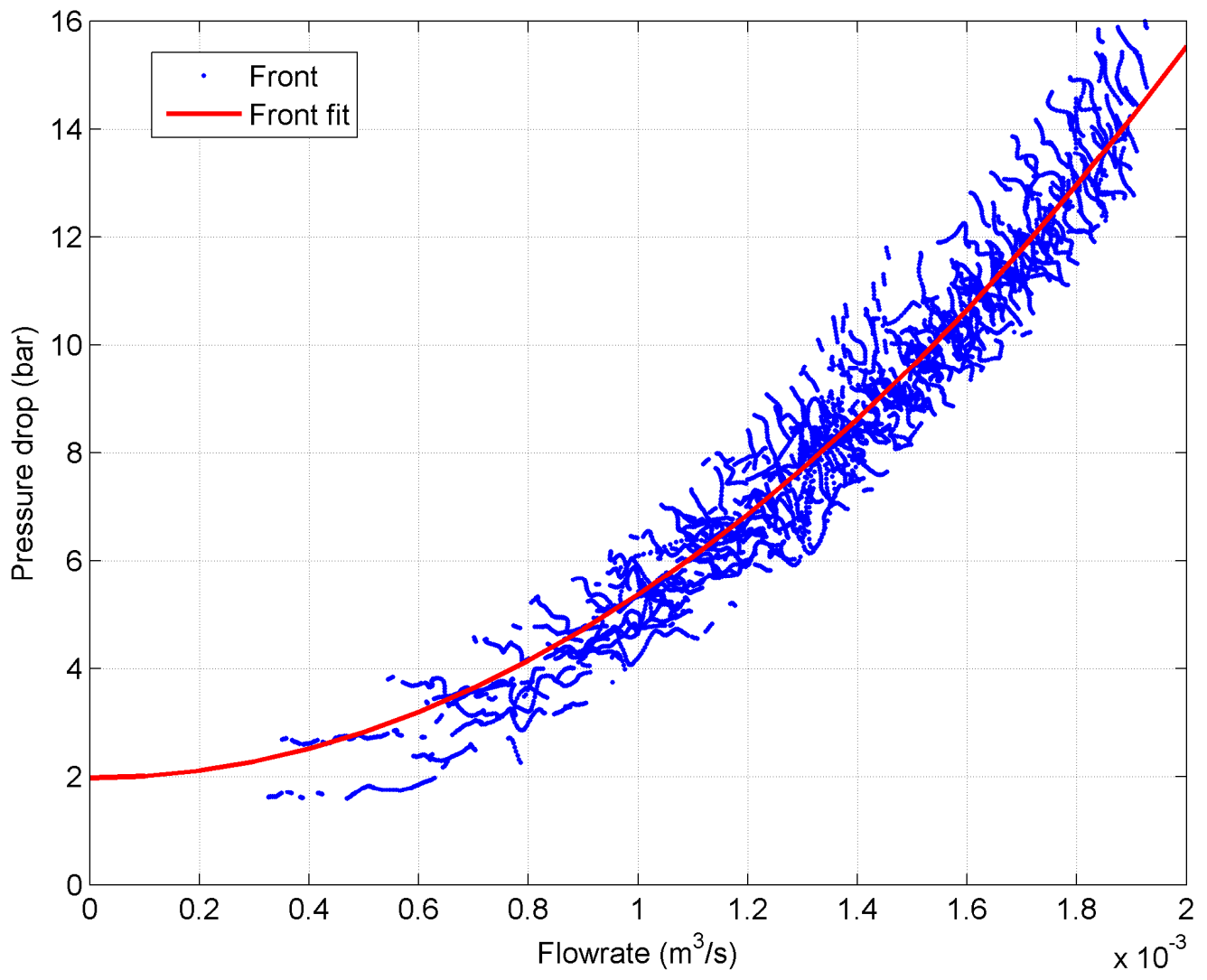

Figure 7: Pressure drop between accumulator and fame rail manifold versus flowrate for several stop-start tests 


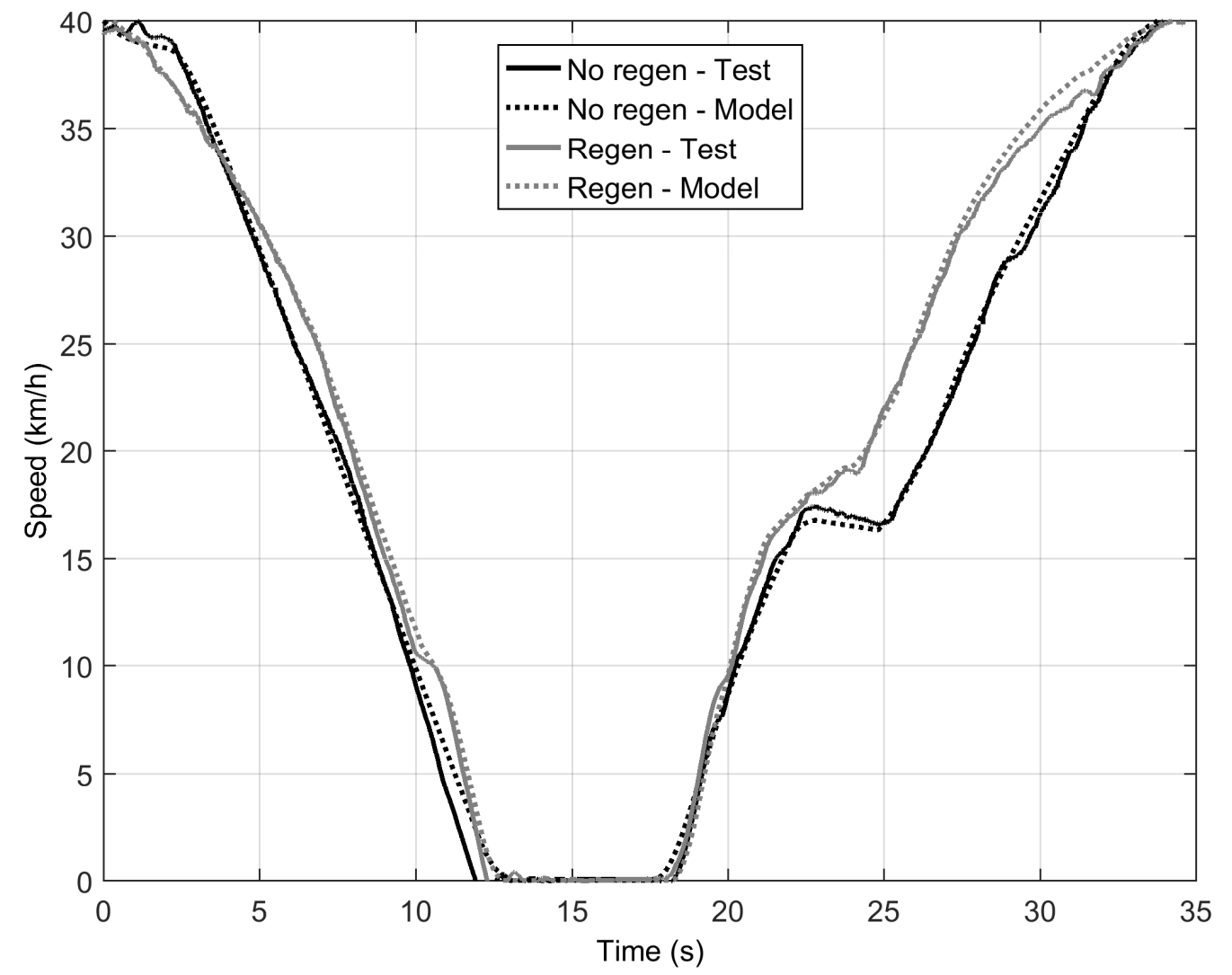

Figure 8: Comparison between test results and model - speed 


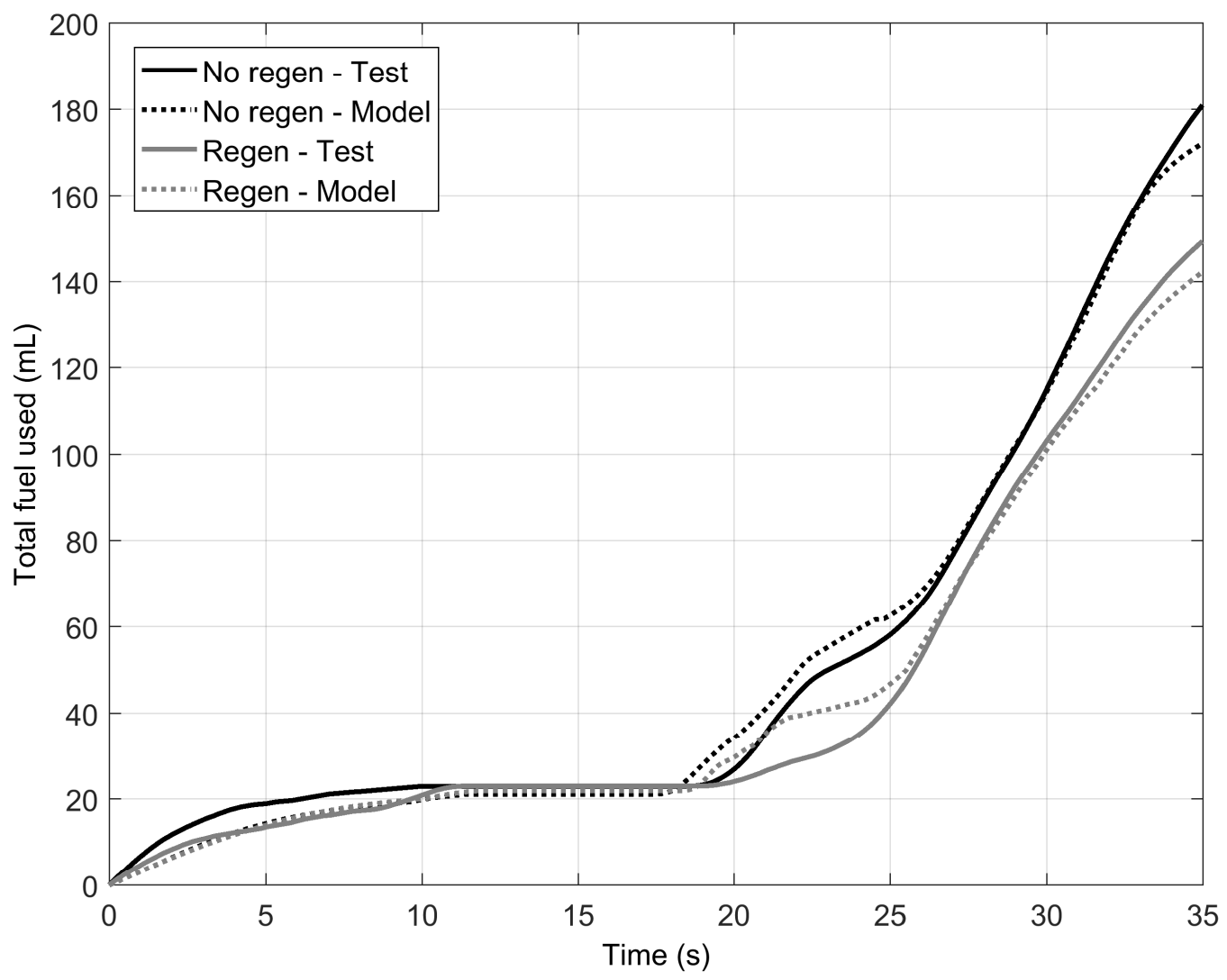

Figure 9: Comparison between test and model - fuel usage 


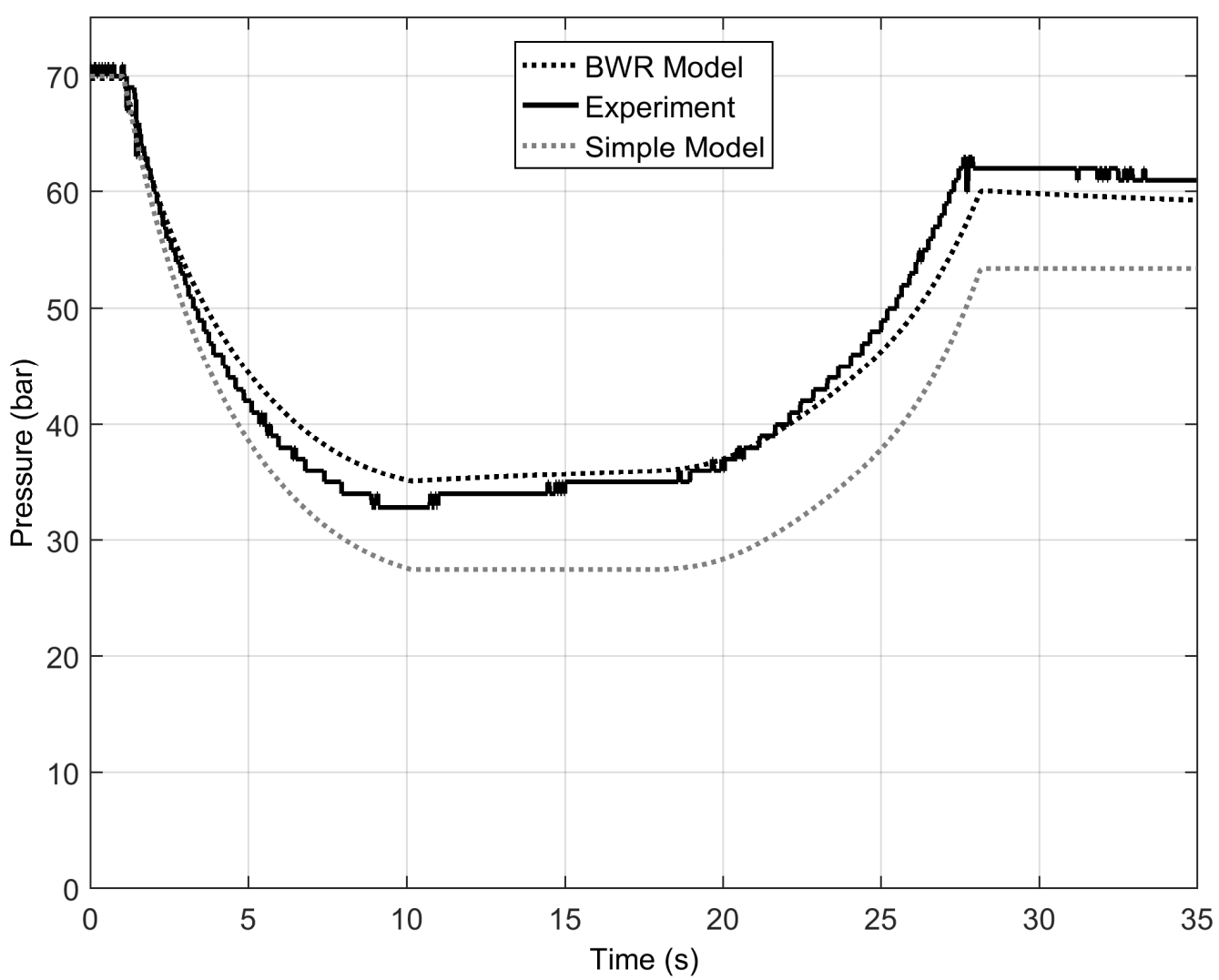

Figure 10: Comparison between improved accumulator model and experimental results: low-pressure accumulator 


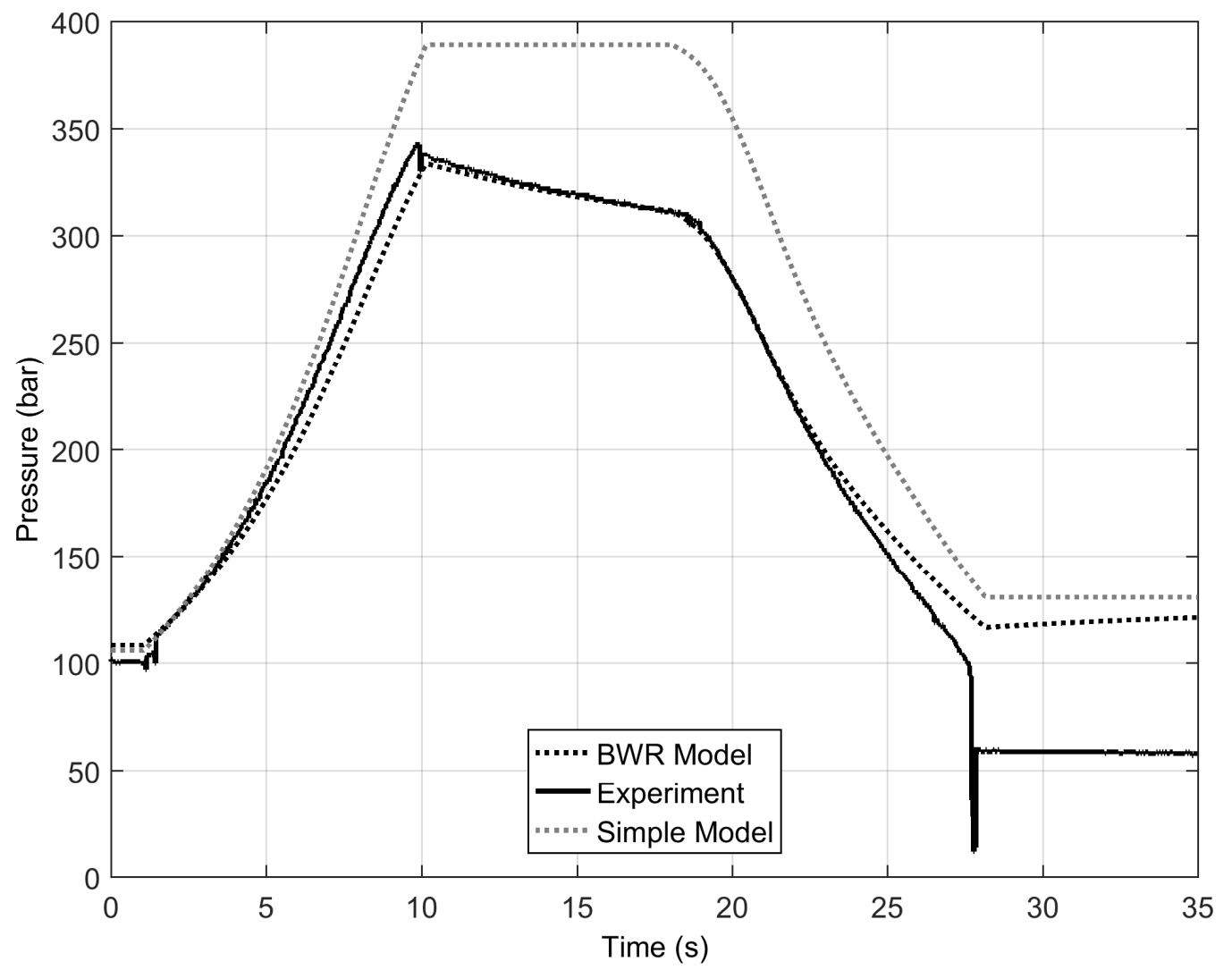

Figure 11: Comparison between improved accumulator model and experimental results: high-pressure accumulator. 

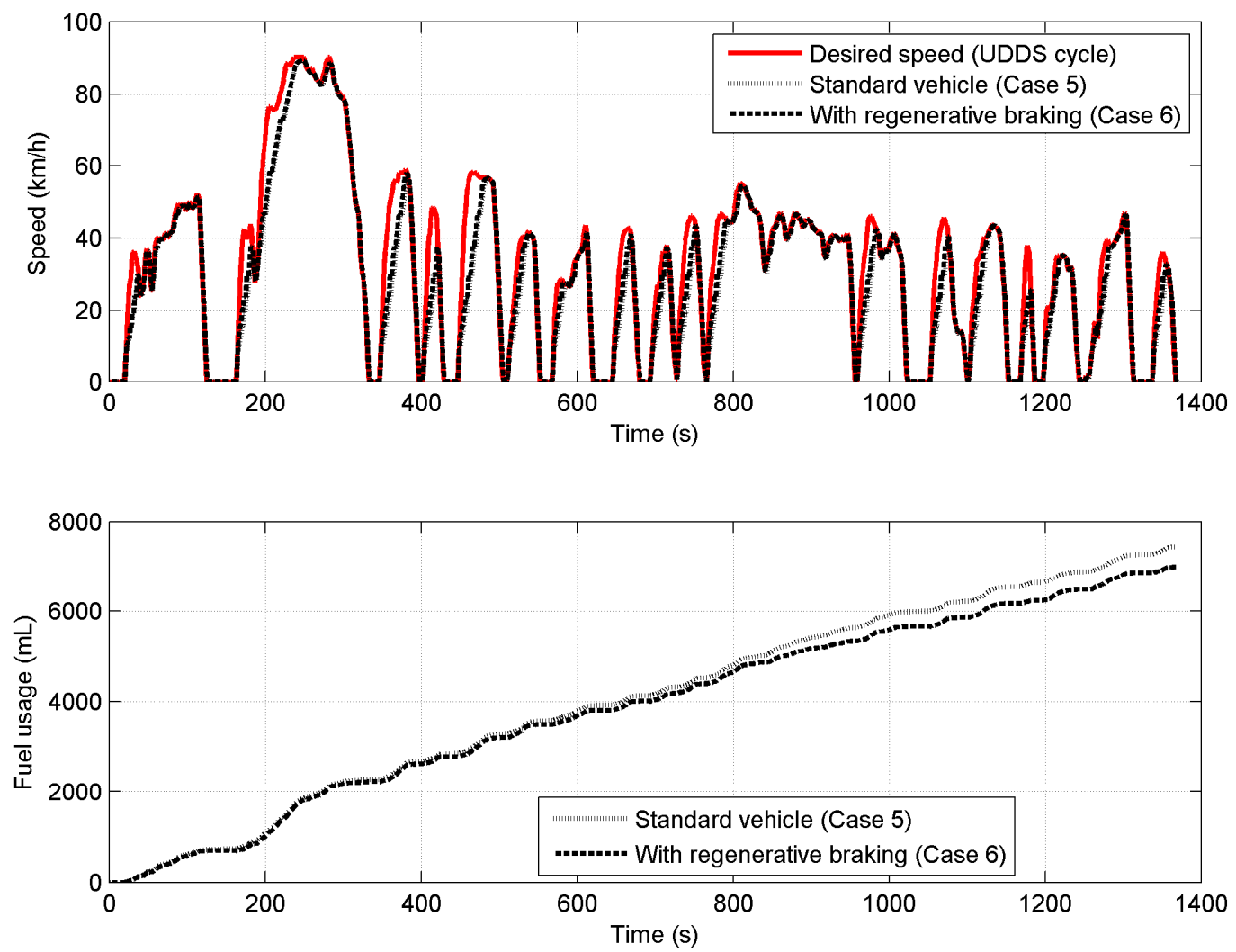

Figure 12: Example results comparing Case 5 and Case 6 for the UDDS Drive Cycle. 

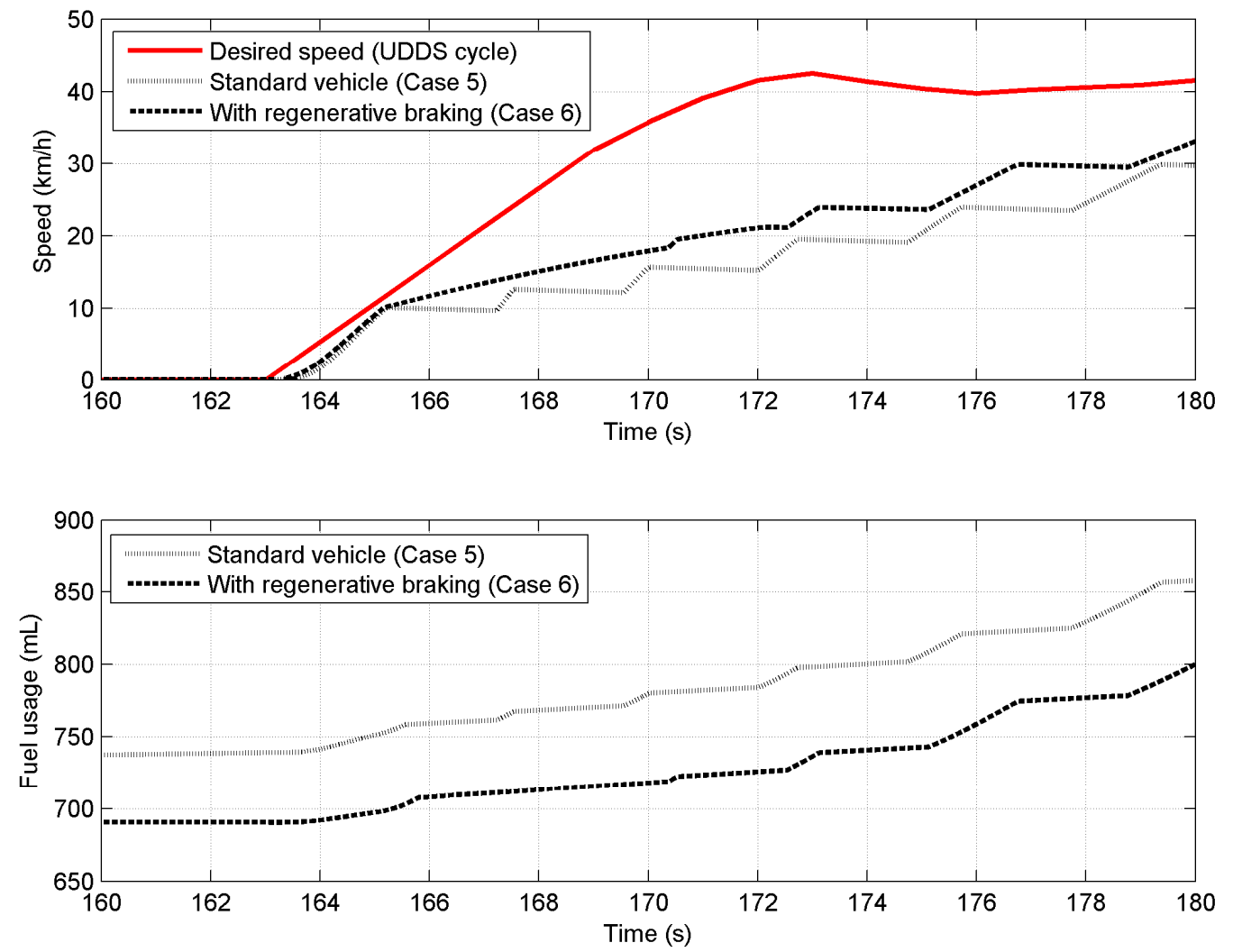

Figure 13: Section of example results, comparing Cases 5 and 6.

\section{Tables}

Table 1: Summary of changes between the system in [10] and the final system

\begin{tabular}{|l|c|c|}
\hline Item & $\begin{array}{c}\text { Specification } \\
\text { in [10] }\end{array}$ & Final system \\
\hline High pressure accumulator volume (litres) & 83.2 & 97 \\
\hline High pressure accumulator precharge pressure (bar) & 130 & 90 \\
\hline Low pressure accumulator volume (litres) & 132 & 145.5 \\
\hline Low pressure accumulator precharge pressure (bar) & 12.5 & 27 \\
\hline Pump/motor displacement (m³/rad) & $9.97 \times 10^{-5}$ & $9.97 \times 10^{-5}$ \\
\hline
\end{tabular}


Table 2: Summary of system component masses

\begin{tabular}{|l|r|r|r|r|}
\hline & \multicolumn{2}{|c|}{ Experimental System } & \multicolumn{2}{c|}{ 'Commercial’ system } \\
\hline Item & Mass (kg) & Mass (\%) & Mass (kg) & Mass (\%) \\
\hline Subframe & 560 & 30.0 & 280 & 25.0 \\
\hline Oil tank & 35 & 1.9 & 0 & 0.0 \\
\hline Hydraulic Oil & 150 & 8.0 & 150 & 13.4 \\
\hline Accumulators & 600 & 32.1 & 188 & 16.8 \\
\hline Accumulator fittings (HP) & 52 & 2.8 & 52 & 4.6 \\
\hline Accumulator fittings (LP) & 48 & 2.6 & 48 & 4.3 \\
\hline Pilot accumulator & 15 & 0.8 & 15 & 1.3 \\
\hline Motor filter block & 6 & 0.3 & 0 & 0.0 \\
\hline Valve manifold (LP) & 20 & 1.1 & 20 & 1.8 \\
\hline Valve manifold (HP) & 135 & 7.2 & 135 & 12.1 \\
\hline Sensor manifold (HP) & 17 & 0.9 & 17 & 1.5 \\
\hline Pilot valve block & 8 & 0.4 & 8 & 0.7 \\
\hline Hydraulic pump & 15 & 0.8 & 0 & 0.0 \\
\hline Regenerative braking valve & 70 & 3.7 & 70 & 6.2 \\
\hline Hydraulic PMs & 116 & 6.2 & 116 & 10.4 \\
\hline HP piping & 21 & 1.1 & 21 & 1.9 \\
\hline & & & & \\
\hline Total & $\mathbf{1 8 6 8}$ & & $\mathbf{1 1 2 0}$ & \\
\hline
\end{tabular}

Table 3: Comparison of loss factors in the circuit

\begin{tabular}{|c|c|c|c|c|}
\hline Section start & Section end & $\begin{array}{c}\mathbf{k} \\
\left(\text { bar.s }^{2} / \mathbf{m}^{6}\right)\end{array}$ & $\begin{array}{c}\Delta \mathbf{P}_{0} \\
\text { (bar) }\end{array}$ & $\begin{array}{l}\text { Percentage } \\
\text { at max flow }\end{array}$ \\
\hline Accumulator manifold (PG1) & Frame rail manifold entry (PG3) & $3.39 E+06$ & 1.97 & \\
\hline Frame rail manifold entry (PG3) & Frame rail manifold exit (PG4) & $3.90 \mathrm{E}+06$ & 0.164 & \\
\hline Frame rail manifold exit (PG4) & Knuckle manifold entry (PG5) & $6.57 \mathrm{E}+06$ & 0.445 & \\
\hline
\end{tabular}

Table 4: Comparison of model and practical tests for stop-start tests

\begin{tabular}{|c|c|l|r|r|}
\hline $\begin{array}{c}\text { Model or } \\
\text { Test }\end{array}$ & Case & \multicolumn{1}{|c|}{ Configuration } & $\begin{array}{r}\text { Vehicle } \\
\text { mass (kg) }\end{array}$ & $\begin{array}{c}\text { Relative } \\
\text { fuel usage } \\
\text { (\%) }\end{array}$ \\
\hline \multirow{2}{*}{ Test } & 1 & Without regenerative braking & 22850 & 100.0 \\
\cline { 2 - 5 } & 2 & With regenerative braking & 22850 & 82.5 \\
\hline \multirow{4}{*}{ Model } & 3 & Without regenerative braking & 22850 & 95.1 \\
\cline { 2 - 5 } & 4 & With regenerative braking & 22850 & 80.5 \\
\cline { 2 - 5 } & 5 & Without regenerative braking (lower mass) & 20982 & 89.1 \\
\cline { 2 - 5 } & 6 & With 'commercial' regenerative braking & 22102 & 78.6 \\
\hline
\end{tabular}


Table 5: Values used for BWR coefficients [23]

\begin{tabular}{|l|l|}
\hline Variable & Value \\
\hline $\mathrm{A}_{0}$ & 1.0673 \\
\hline $\mathrm{B}_{0}$ & 0.04074 \\
\hline $\mathrm{C}_{0}$ & $8.164 \times 10^{3}$ \\
\hline $\mathrm{a}$ & 0.0254 \\
\hline $\mathrm{b}$ & 0.002328 \\
\hline $\mathrm{c}$ & $7.379 \times 10^{2}$ \\
\hline$\alpha$ & $1.272 \times 10^{-4}$ \\
\hline$\gamma$ & 0.0053 \\
\hline
\end{tabular}

Table 6: Baseline vehicle parameters (from [1]) (Exp. - Experimental, Com. - Commercial)

\begin{tabular}{|c|c|c|c|c|c|c|c|}
\hline Vehicle & $\begin{array}{c}\text { Maximum } \\
\text { mass (t) }\end{array}$ & $\begin{array}{c}\text { Unladen } \\
\text { mass (t) }\end{array}$ & $\begin{array}{c}\text { Max. } \\
\text { Payload } \\
\text { mass (t) }\end{array}$ & $\begin{array}{c}\text { Laden } \\
\text { gross } \\
\text { vehicle } \\
\text { mass (t) }\end{array}$ & $\begin{array}{c}\text { Max. } \\
\text { payload } \\
\text { Volume } \\
\left(\mathbf{m}^{3}\right)\end{array}$ & $\begin{array}{c}\text { Max. } \\
\text { Engine } \\
\text { Power } \\
(\mathbf{k W})\end{array}$ & $\begin{array}{c}\text { Drag } \\
\text { coefficient } \\
\left.-\mathbf{C}_{\mathrm{d} A} \mathbf{( m}^{2}\right)\end{array}$ \\
\hline Rigid & 26 & 9.7 & 16.3 & 26 & 39.4 & 206 & 3.95 \\
\hline $\begin{array}{c}\text { Articulated - } \\
\text { Conventional }\end{array}$ & 44 & 14.9 & 29.1 & 44 & 84.2 & 336 & 6.62 \\
\hline $\begin{array}{c}\text { Articulated - } \\
\text { Regenerative } \\
\text { braking (Exp.) }\end{array}$ & 44 & 16.8 & 27.2 & 44 & 84.2 & 336 & 6.62 \\
\hline $\begin{array}{c}\text { Articulated - } \\
\text { Regenerative } \\
\text { braking (Com.) }\end{array}$ & 44 & 16.0 & 28 & 44 & 84.2 & 336 & 6.62 \\
\hline
\end{tabular}

Table 7: EIv saving compared to conventional articulated vehicle using 90bar precharge pressure

\begin{tabular}{|l|c|c|}
\cline { 2 - 3 } \multicolumn{1}{c|}{ Cycle } & \multicolumn{2}{|c|}{ EIv reduction (\%) } \\
\hline $\begin{array}{c}\text { Articulated } \\
\text { vehicle with } \\
\text { Regenerative } \\
\text { braking }\end{array}$ & $\begin{array}{c}\text { Articulated } \\
\text { vehicle with } \\
\text { Regenerative } \\
\text { braking and } \\
\text { stop-start }\end{array}$ \\
\hline UDDS & $0.1 \%$ & $1.8 \%$ \\
\hline HHDDT-T & $1.7 \%$ & $3.3 \%$ \\
\hline NEDC & $-0.3 \%$ & $2.2 \%$ \\
\hline NYC & $2.1 \%$ & $8.7 \%$ \\
\hline
\end{tabular}


Table 8: Simulated fuel savings using higher precharge pressure

\begin{tabular}{|c|c|c|c|c|c|}
\hline & \multicolumn{2}{|c|}{$\begin{array}{c}\text { EIv reduction (\%) compared to } \\
\text { conventional artic. }\end{array}$} & \multicolumn{2}{|c|}{ EIv reduction $(\%)$ compared to rigid } & \multirow{2}{*}{$\begin{array}{c}\text { Precharge } \\
\text { pressure } \\
\text { (bar) }\end{array}$} \\
\hline & $\begin{array}{l}\text { Regenerative } \\
\text { braking }\end{array}$ & $\begin{array}{c}\text { Regenerative } \\
\text { braking and } \\
\text { stop-start }\end{array}$ & $\begin{array}{l}\text { Regenerative } \\
\text { braking }\end{array}$ & $\begin{array}{c}\text { Regenerative } \\
\text { braking and } \\
\text { stop-start }\end{array}$ & \\
\hline UDDS & $7.5 \%$ & $9.2 \%$ & $34 \%$ & $35 \%$ & 200 \\
\hline HDDDT-T & $6.6 \%$ & $8.2 \%$ & $37 \%$ & $38 \%$ & 170 \\
\hline NEDC & $4.1 \%$ & $6.5 \%$ & $34 \%$ & $36 \%$ & 240 \\
\hline NYC & $12.2 \%$ & $18.1 \%$ & $38 \%$ & $42 \%$ & 220 \\
\hline
\end{tabular}

\section{Acknowledgements}

The authors would like to thank Poclain Hydraulics for their support, as well as Team MRO for their help with this research. Additionally, none of this research would have been possible without the generous technical support of the Cambridge Vehicle Dynamics Consortium whose members at the time of writing were: Camcon, Denby Transport, Firestone Industrial Products, Goodyear Tires, Haldex Brake Products, SDC Trailers, SIMPACK, MIRA, Poclain Hydraulics, Tinsley Bridge, Tridec BV and Volvo Trucks. This research would not have been undertaken without the financial support of the Centre for Sustainable Road Freight www.csrf.ac.uk.

\section{Funding}

This work was supported by the Cambridge Vehicle Dynamics Consortium, the Centre for Sustainable Road Freight and the Engineering and Physical Sciences Research Council (grant number EP/K00915X/).

\section{References}

[1] A. M. C. Odhams, R. L. Roebuck, Y. J. Lee, S. W. Hunt, and D. Cebon, "Factors Influencing the Energy Consumption of Road Freight Transport," Proc IMechE Part C, J Mech Eng Sci, vol. 224, pp. 1995-2010, 2010.

[2] B. A. Jujnovich and D. Cebon, "Path-Following Steering Control for Articulated Vehicles," ASME Journal of Dynamic Systems, Measurement, and Control, vol. 135, pp. 031006-031006, 2013.

[3] W. J. Midgley and D. Cebon, "Comparison of regenerative braking technologies for heavy goods vehicles in urban environments," Proceedings of the Institution of Mechanical Engineers, Part D: Journal of Automobile Engineering, vol. 226, pp. 957-970, July 1, 20122012.

[4] A. M. Klemp. The Business of Big Hybrids. Diesel Progress. 12-16. Available: http://www.parker.com/literature/Hydraulics\%20Group\%20US/Big Hybrids Diesel Progress_Feb10.pdf

[5] "Parker RunWise Advanced Series Hybrid Drive," ed: System Brochure - Parker Hydraulics, 2011. 
[6] D. J. Cole, A. C. Collop, T. E. C. Potter, and D. Cebon, "Spatial repeatability of measured dynamic tyre forces," J. Auto. Eng, IMech E, vol. 210, pp. 185-197, 1996.

[7] M. EauClaire. (2008, March 2008) Joining Forces. OEM Off-Highway. 40-47.

[8] G. Ehrenman, "Look, Ma, No Transmission," Mechanical Engineering, vol. 127, pp. 2426, 2005.

[9] W. Flugge, Viscoelasticity: Blaisdell Publishing Company, 1967.

[10] W. J. B. Midgley, H. Cathcart, and D. Cebon, "Modelling of hydraulic regenerative braking systems for heavy vehicles," Proceedings of the Institution of Mechanical Engineers, Part D: Journal of Automobile Engineering, vol. 227, pp. 1072-1084, July 1, 20132013.

[11] W. J. B. Midgley and D. Cebon, "Design and Specification of Hydraulic Hybrid System for HGVs," presented at the HVTT 2014, San Luis, Argentina, 2014.

[12] S. W. Hunt, A. M. C. Odhams, R. L. Roebuck, and D. Cebon, "Parameter measurement for heavy-vehicle fuel consumption modelling," Proceedings of the Institution of Mechanical Engineers, Part D: Journal of Automobile Engineering, vol. 225, pp. 567-589, May 1, 20112010.

[13] W. J. B. Midgley, "Regenerative Braking of Urban Delivery Heavy Goods Vehicles," $\mathrm{PhD}$, Department of Engineering, University of Cambridge, 2012.

[14] "Volvo FE Hybrid," ed: Volvo Truck Corporation, 2011.

[15] W. J. B. Midgley and D. Cebon, "Control of a Hydraulic Regenerative Braking System for Heavy Goods Vehicles," Sub. J Auto Eng, 2014.

[16] A. M. C. Odhams, R. L. Roebuck, B. A. Jujnovich, and D. Cebon, "Active steering of a tractor--semi-trailer," Proceedings of the Institution of Mechanical Engineers, Part D: Journal of Automobile Engineering, vol. 225, pp. 847-869, July 1, 2011.

[17] B. Jujnovich, R. Roebuck, A. Odhams, and D. Cebon, "Implementation of active rear steering of a tractor -- semi-trailer," presented at the Heavy Vehicle Transport Technology 10, Paris, 2008.

[18] "11898-1:2003 Road vehicles -- Controller area network (CAN)," ed: International Standards Organisation, 2003.

[19] "RT3000 Inertial and GPS Navigation System," ed. Oxford Technical Solutions. Last accessed 27/09/2015: http://www.oxts.com/Downloads/Products/RT3000/RT3000Single-Antenna.pdf, 2012.

[20] M. Benedict, G. B. Webb, and L. C. Rubin, "An Empirical Equation for Thermodynamic Properties of Light Hydrocarbons and Their Mixtures I. Methane, Ethane, Propane and n - Butane," The Journal of Chemical Physics, vol. 8, pp. 334-345, 1940.

[21] H. B. Hansen and P. W. Rasmussen, "Modeling Hydraulic Accumulators for use in Wind Turbines," presented at the The 13th Scandinavian International Conference on Fluid Power, Linköping, Sweden, 2013.

[22] D. R. Otis and A. Pourmovahed, "An Algorithm for Computing Nonflow Gas Processes in Gas Springs and Hydropneumatic Accumulators," Journal of Dynamic Systems, Measurement, and Control, vol. 107, pp. 93-96, 1985.

[23] H. W. Cooper and J. C. Goldfrank, "B-W-R Constants and New Correlations," Hydrocarbon Processing, vol. 46, pp. 141-146, 1967.

[24] "Bottom Repairable Lightweight High Pressure Compostie Accumulator," ed. Steelhead Composites. Last accessed 17/10/2015: http://steelheadcomposites.com/shc/wp-content/uploads/2015/05/SHC-BR6000.pdf, 2014. 
[25] A. C. Collop, D. Cebon, and M. S. A. Hardy, "A visco-elastic approach to rutting in flexible pavements," ASCE Journal of Transportation Engineering, vol. 121, pp. 82-93, 1995.

[26] R. Radlinski, "Development of a truck-tractor pneumatic simulator and optimization of trailer air brake plumbing," Vehicle Research and Test Center, National Highway Traffic Safety Administration, U.S. Dept. of Transport., Memorandum Report CAR-5, April, 19811981.

[27] T. M. Post, P. S. Fancher, and J. E. Bernard, "Torque characteristics of commercial vehicle brakes," SAE 750210, 1975.

[28] "FE 26 Tonne 6x4 B Ride Rigid - data sheet," ed: Volvo Trucks, last accessed: 2014-0404, available at http://www.volvotrucks.com/sitecollectiondocuments/vtc/uk/trucks/fe/fe64bride.pdf, 2008.

[29] Z. Filipi and Y. J. Kim, "Hydraulic Hybrid Propulsion for Heavy Vehicles: Combining the Simulation and Engine-In-the-Loop Techniques to Maximize the Fuel Economy and Emission Benefits," Oil Gas Sci. Technol., vol. 65, pp. 155-178, 2010.

[30] A. Pourmovahed, N. H. Beachley, and F. J. Fronczak, "Modeling of a Hydraulic Energy Regeneration System: Part II---Experimental Program," Journal of Dynamic Systems, Measurement, and Control, vol. 114, pp. 160-165, 1992.

For access to the raw data used in the production of this paper, please see:

http://www.repository.cam.ac.uk/handle/1810/248831 